\title{
QUATRO R: CONCEITO FUNDAMENTAL PARA A GESTÃO DO LIXO
}

Rodrigo Coladello Oliveira, Lucas Prado Osco, Marcos Norberto Boin, Maurício Waldman

Universidade do Oeste Paulista - UNOESTE, Mestrado em Meio Ambiente e Desenvolvimento Regional, Presidente Prudente, SP. e-mail: pradoosco@gmail.com

\section{RESUMO}

O presente artigo teve como objetivo apresentar e discutir a respeito dos conceitos essenciais da gestão dos resíduos sólidos, priorizando práticas de participação da sociedade, bem como atitudes que contribuem para o manuseio adequado dos resíduos, incluindo, neste contexto, a atitude de repensar. Buscou-se apoio teórico em trabalhos que pautam a questão conceitual da gestão do lixo, e que, por ventura, poderiam contribuir para as reflexões e discussões dos resultados deste artigo. Observa-se a necessidade de abordar a questão dos resíduos sólidos de maneira integrada ao cenário em que o mesmo constitui-se, seja no aspecto social, econômico ou ambiental. Portanto, ressalta-se que a tríade temática apresentada neste trabalho atua como um excelente critério de análise dos resíduos, e, associado à integração da sociedade, contribuem substancialmente para a gestão dos resíduos sólidos.

Palavras-chave: Gestão, Resíduos Sólidos, Conceitos, Quatro R.

\begin{abstract}
This article aims to present and discuss about the essential concepts of the solid waste management, prioritizing practices of social participation and attitudes that contribute to the proper handling of waste, including in this context, the attitude of rethinking. We sought a theoretical support work that guided the conceptual issue of waste management, and that, perhaps, could contribute to the reflections and discussions of the results on this article. Therefore, we observed the needs in adressing the issue of solid waste in an integrated scenario in which it is constituted of social, economic or environmental aspects. Thus, we emphasize about the thematic triad presented in this paper, whitch serves as an excellent criterion of residue analysis, and associated with the integration of society, substantially contributing to the management of solid waste.
\end{abstract}

Keywords: Management, Solid Waste, Concepts, Four R. 


\section{INTRODUÇÃO E OBJETIVO}

Existem metodologias para a gestão do lixo que possuem caráter participativo, das quais indicam soluções e atitudes advindas de interessados (comunidade), que por sua vez, contribuem para 0 aperfeiçoamento e consolidação de etapas de implantação e/ou funcionamento do gerenciamento dos resíduos. Para tanto, Castilho Junior (2003) acrescenta que se devem considerar o compartilhamento do conhecimento sobre a relação entre saneamento ambiental, saúde e resíduos sólidos, pois permitirá conciliar o aspecto técnico-ambiental com a realidade social, cultural e econômica da comunidade.

Além disso, outra relação de considerável atração é a da tríade temática dos recursos hídricos, resíduos sólidos e matriz energética, que conforme Waldman (2013) se faz necessário analisá-los em conjunto para promover o debate conceitual integrado e compreender a complexidade da rede de relacionamentos deste trinômio.

Elucidar os elementos conceituais de gestão do lixo também é importante, pois contribui sobremaneira para práticas de gerenciamento de resíduos e em medidas preventivas, cabendo ressaltar os "Quatro R", utilizados por muitos autores da área de resíduos, e por programas que estimulam o manejo adequado ao lixo. Alguns utilizam apenas dois R, reduzir e reaproveitar (VALLE,
2002), porém, é necessário a complementação dos demais $\mathrm{R}$, repensar $\mathrm{e}$ reciclar, cuja sequência metodológica foi compreendida nos resultados do presente trabalho.

Considerando a essencialidade estratégica da gestão do lixo e transcendendo-a para a prática, a investigação popular possui importante função para o planejamento (STROH, 2003), onde por meio desta é possível identificar configurações sociais, promover o entendimento e a explicação de mecanismos essenciais de funcionamento e reprodução da sociedade. Desta forma, a participação social auxilia o estabelecimento de ferramentas capazes de definirem políticas, planos, projetos e programas voltados ao lixo.

Assim, o presente artigo buscou realizar um debate conceitual a respeito da gestão e gerenciamento do lixo sob a perspectiva dos $4 R$, associando a proposição da tríade temática, e, a participação da sociedade.

\section{METODOLOGIA}

Para a elaboração do presente artigo, embasou-se nos textos de Waldman (2003, 2013a, 2013b) sobre gestão dos resíduos, adjuntos das diretrizes observadas na lei vigente 12.3005/10 (Política Nacional de Resíduos Sólidos - PNRS), buscando 
apresentar um debate reflexivo relacionado ao acréscimo do repensar da política dos $4 \mathrm{R}$, bem como da participação social no gerenciamento dos resíduos.

\section{RESULTADOS E DISCUSSÕES}

No que diz respeito à preocupação inerente aos resíduos sólidos, deve-se, preliminarmente, atestar algumas considerações iniciais e essenciais à sua compreensão. Em conformidade com a Política Nacional de Resíduos Sólidos (PNRS) (BRASIL, 2010), no Art. 3, XVI, a conceituação de resíduos sólidos é dada nos seguintes dizeres:

[...] material, substância, objeto ou bem descartado resultante de atividades humanas em sociedade, a cuja destinação final se procede, se propõe proceder ou se está obrigado a proceder, nos estados sólido ou semissólido, bem como gases contidos em recipientes e líquidos cujas particularidades tornem inviável o seu lançamento na rede pública de esgotos ou em corpos d'água, ou exijam para isso soluções técnica ou economicamente inviáveis em face da melhor tecnologia disponível.

Quando referente à distinção terminológica, os resíduos diferem dos então denominados rejeitos, associados comumente ao lixo inservível, que por definição, como consta na Lei da PNRS, (BRASIL, 2010), Art. 3, XV, são:

[...] resíduos sólidos que, depois de esgotadas todas as possibilidades de tratamento e recuperação por processos tecnológicos disponíveis e economicamente viáveis, não apresentem outra possibilidade que não a disposição final ambientalmente adequada.

Diante disto, é evidente a disparidade entre ambos os termos perante a legislação vigente. Entretanto, colocações como estas tendem a conduzir o enfoque dado às práticas de gerenciamento dos resíduos sólidos para outros âmbitos, distanciando a problemática de seu ponto de origem, e, ainda, dando a entender que técnicas de reciclabilidade e disposição final "ambientalmente adequada" tornam-se os mecanismos ideais (se não únicos) para solucionar a questão dos resíduos. Deve-se, substancialmente, compreender a existência de alternativas e métodos que, por intuito, buscam disponibilizar maneiras de lidar com o lixo de forma condizente.

Em razão disto, percebe-se que ponderar acerca desta problemática envolve uma série de considerações que, majoritariamente, são pouco difundidas ou até mesmo negligenciadas no debate abordado. Neste sentido, entende-se a importância do emprego de avaliações 
relativas a todo um processo coexistente por detrás da confecção da matéria (ou produto) em si, que adiante há de se tornar o resíduo. Para tanto, salienta-se uma interligação entre os resíduos sólidos, os recursos hídricos e a matriz energética (Figura 1), pois se subentende que não há condições de abordar o tema - com a eficácia necessária caso esta temática encontrar-se fragmentada.

Figura 1. Tríade Temática: Uma Proposição Gráfica.

\section{TRÍADE TEMÁTICA: UMA PROPOSIÇÃO GRÁFICA}

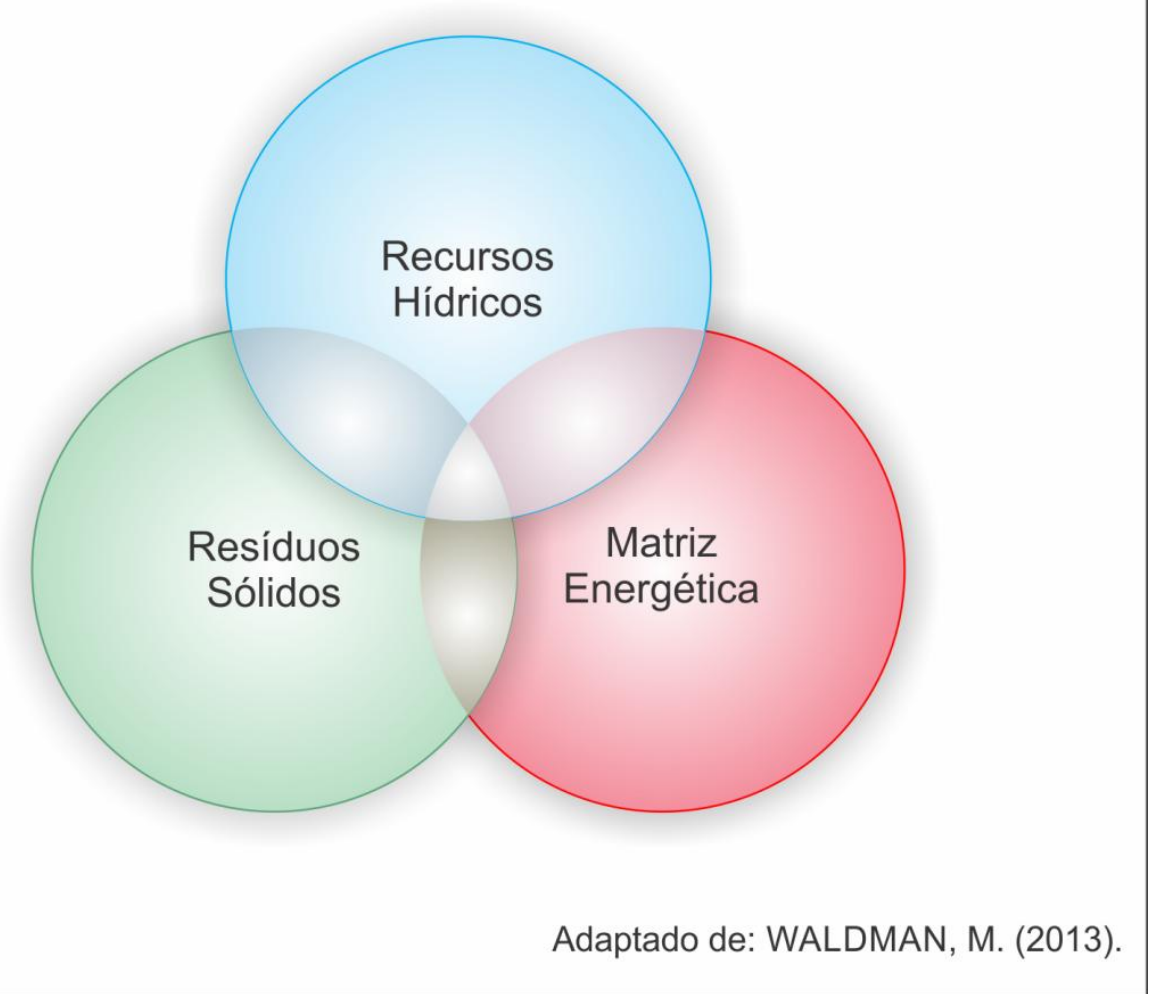

Logo, é inegável que a utilização de qualquer um dos recursos mencionados acima tende a empreender uma correlação entre os mesmos. Neste sentido, nos dizeres de Waldman (2013, p. 51), “[...] não há e jamais haverá qualquer debate sério sobre recursos hídricos, resíduos sólidos e matriz energética, habilitado a dispensar uma intersecção temática cujo nexo reporta à complexa rede de relacionamentos concretos mantidos entre estas três esferas.". Torna-se, portanto, implícito a obrigação de se refletir a respeito da coexistência abarcada por um trinômio tanto altercado como este.

Assim, ao adotarem-se medidas que visem o gerenciamento dos resíduos, não se pode permitir a exclusão do recurso hídrico e da energia elétrica que se encontram 
concentrados ao longo das diversas fases de vida do material, desde sua produção até o descarte. Consecutivamente, para que se consiga atingir índices satisfatórios mediante a este gerenciamento, é essencial a fundamentação e o planejamento adequados. Dentre as práticas vitais nestas diretrizes, ressalta-se a incorporação dos Três R's (reduzir, reutilizar e reciclar), que, posteriormente, passaram a englobar outras nomenclaturas. Estas, por outro lado, podem ser sintetizadas em outro $\mathrm{R}$ (repensar), consolidando a atualmente difundida: Quatro R's (Figura 2).

Figura 2. Quatro R (Repensar; Reduzir; Reutilizar e; Reciclar).

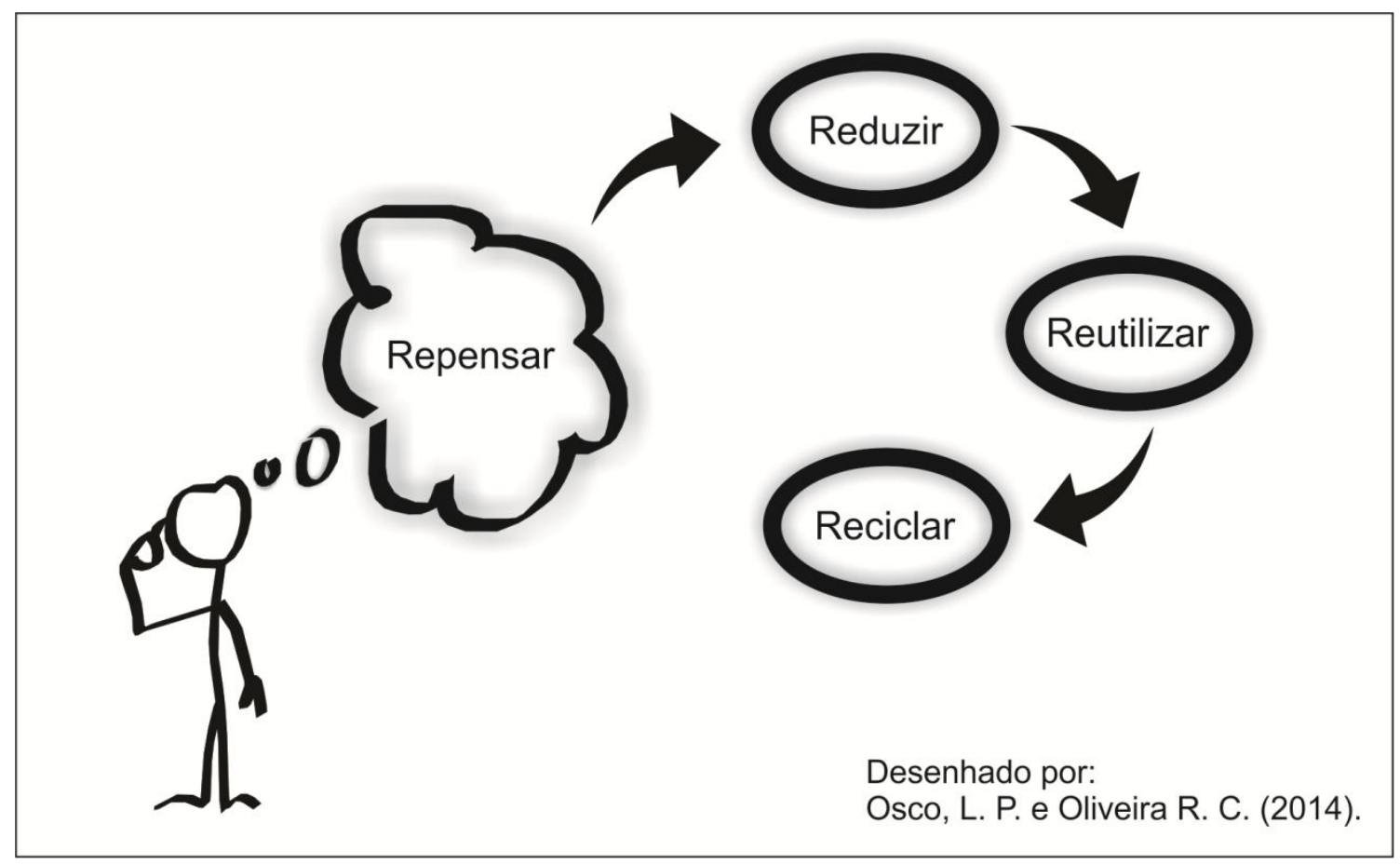

Ao passo que o conhecimento científico avança tecnologicamente, engendram-se distintas alternativas para a reciclagem destes materiais. Entretanto, conforme ilustrado na Figura 2, o ato de reciclar deveria, ao menos, ser a última estância, posta em exercício somente quando comprovada a ineficiência dos demais R's. A reutilização, por outro lado, consiste-se em uma prática interessante e ainda há de ser mais bem explorada. Não se deve, apesar destas considerações, admitir que somente o reaproveitamento do material descartado seja o suficiente para conter e solucionar a questão do lixo, pois embora ambas possuam maiores incentivos - parte em razão do interesse econômico embutido em suas atividades -, existe um consenso científico sobre os fatores limitantes (para a 
reciclagem) e do tempo de vida do material (para a reutilização).

Reduzir o montante de resíduos sólidos produzidos apresenta-se (na concepção inicial dos R's) como a melhor opção diante da problemática envolvida, porém pouco difundida e raramente desempenhada devido à consequência econômica que a não geração destes resíduos implica, uma vez que para tal tornase necessário à redução do consumo, e, portanto, da confecção de novos produtos. Por conseguinte, há de se examinar a situação, justificando o acréscimo do novo $R$, com o intuito de repensar esta questão, tendo em vista realizar-se ao menos uma concepção recíproca entre o desenvolvimento econômico e o meio ambiente. Para tanto, práticas de gerenciamento integrado tem se mostrado uma alternativa viável em relação ao manuseio e cuidados atinentes aos resíduos sólidos, sejam estes advindos de atividades empresariais, urbanas e/ou domésticas.

Destarte, embora o termo "repensar" não seja diretamente explícito, o Ministério do Meio Ambiente - MMA (BRASIL, 2012) exibe elementos substanciais para a gestão dos resíduos sólidos. Em primeiro lugar encontra-se a não geração, que em "lato sensu", engloba - indiretamente - a atitude de repensar. Assim, seguem-se os demais fatores: reduzir; reutilizar; reciclar; tratar; e dispor "adequadamente" os resíduos (Figura $3)$.

Figura 3. Fatores Essenciais Para a Gestão dos Resíduos Sólidos.

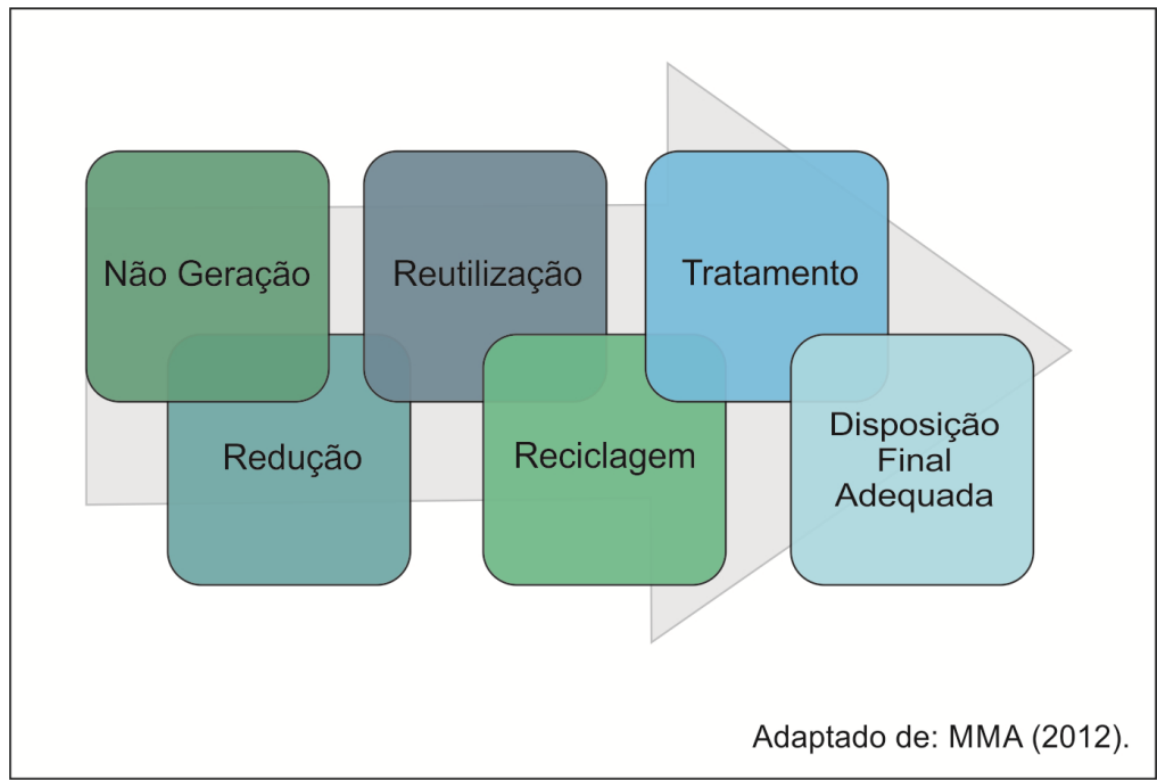


Como critério elucidativo, salienta-se que as terminologias gestão e gerenciamento possuem conotações distintas, e que, frequentemente, são confundidas como sinônimos. A primeira associa-se às tomadas de decisões, procedimentos e articulações que estejam voltadas ao âmbito das estratégias, enquanto que a segunda referese ao caráter operacional, como, por exemplo, a efetivação da limpeza urbana.

Todos os planejamentos e estratégias de gestão que evolvam o gerenciamento dos resíduos sólidos, política de redução de lixo, educação ambiental, dentre outras, necessitam da integração e participação assídua da sociedade, conferindo à comunidade um elemento importante, quiçá, a força motriz para que as estratégias de gestão do lixo concretizem-se. Para tanto, as atitudes e hábitos da população devem ser impreterivelmente repensados, sendo que:

\begin{tabular}{|c|}
\hline $\begin{array}{l}\text { epensar significa men } \\
\text { mbalagens } \\
\text { lercadorias; significa } \\
\text { tilização de quantidad } \\
\text { ínimas de alumín } \\
\text { gnifica menor utilizaç } \\
\text { e petróleo na produção } \\
\text { nergia e menor consun } \\
\text { a distribuição; signifi } \\
\text { enor desperdício p } \\
\text { arte de cidadã } \\
\text { onscientes } \\
\text { otencialidades inerentes } \\
\text { la atitude individu } \\
\text { gnifica consun } \\
\text { sponsável; signifi } \\
\text { enor consumismo, un } \\
\text { da de simplicida }\end{array}$ \\
\hline
\end{tabular}

voluntária atendo-se ao que de fato é essencial e importante para o futuro da sociedade humana; significa enfim uma vida visceralmente comunitária, com cidadãos integrados no contexto do seu espaço de vida imediato e com meio social no seio do qual vivem e reproduzem as suas esperanças (WALDMAN, 2003, p. 7).

Evidentemente, ao passo em que se conceituam os mecanismos de gestão do lixo, emerge-se a necessidade de contextualizá-los junto às esferas sociais, econômicas, culturais e tecnológicas envolvidas. Deste modo, a integração destes fatores implica no aprimoramento da gestão do lixo, visto que ao englobar as condicionantes essenciais ao processo de gestão, este, tornar-se-á harmônico e aplicável para todas as esferas, principalmente à comunidade.

\section{CONCLUSÃO}

Portanto, os conceitos fundamentais para a gestão do lixo perpassam por diversas interfaces, que quando abordadas de modo holístico, ou seja, quando os elementos envolvidos são analisados de modo integrado, contribuem substancialmente para o processo de gestão e, consequentemente, de gerenciamento do lixo, visto que, nos pensamentos de Milton Santos (1978, 1988, 1998 apud WALDMAN, 
2013, p. 3), “[...] os detritos expressam inextricável fatoração espacial. Na lógica da organização do espaço, catalisam, formatam e direcionam fluxos ${ }^{1},[\ldots]$ e ao mesmo tempo, endossam atribuições delegadas aos fixos ${ }^{2 \prime \prime}$.

\section{REFERÊNCIAS}

BRASIL. Congresso Nacional. Política Nacional de Resíduos Sólidos. Lei n.o 12.305, de 2 de Agosto de 2010. Dispõe sobre seus princípios, objetivos e instrumentos. Diário Oficial da União, Brasília, DF. Disponível em: <http://www.mma.gov.br/port/conama/legia bre.cfm?codlegi=636>. Acesso em: 16 jul. 2014.

BRASIL. Ministério do Meio Ambiente. Planos de gestão de resíduos sólidos: manual de orientação. Brasília: Ministério do Meio Ambiente, 2012.

CASTILHO JUNIOR, A. B. (coord.). Resíduos sólidos urbanos: aterro sustentável para municípios de pequeno porte. 1. ed. Rio de Janeiro: ABES, 2003.

WALDMAN, M. Água, lixo e energia: proposições teóricas para uma tríade temática. In: SEMANA DE CIÊNCIA E TECNOLOGIA. Anais... Instituto Federal de Minas Gerais, Campus de Ouro Preto, 2013a.

WALDMAN, M. Mais água, menos lixo: reciclar ou repensar? Boletim Paulista de Geografia (BPG), n.79, p. 91-106, 2003.

\footnotetext{
${ }^{1}$ Conceitualização criada por Milton Santos durante a década dos anos 70, utilizado como base epistemológica do autor para referir-se à dinâmica do espaço, usado para expressar a relação entre sistemas de objetos e sistemas de ações. Os fluxos são cada vez mais amplos, numerosos e rápidos. (SANTOS, 1999 apud WALDMAN, 2013). Exemplo: serviços de limpeza pública, coleta seletiva, entre outros.

${ }^{2}$ Os fixos estão relacionados aos fluxos, dos quais mantém perpétua interação, onde os fixos e os fluxos, ao interagirem expressam a realidade geográfica. Os fixos são cada vez mais artificiais e fixados ao solo. (SANTOS, 1999 apud WALDMAN, 2013). Exemplo: Aterros de resíduos, centrais de triagem e compostagem, entre outros.
}

WALDMAN, M. Para repensar os resíduos sólidos: notas sobre o pensamento vivo de Milton Santos. In: CONFERÊNCIA REGIONAL DO MEIO AMBIENTE DO GRANDE ABC Resíduos Sólidos, 1. Anais... Santo André (SP): Consórcio Intermunicipal do Grande $A B C, 2013 b$.

STROH, P. Y. As Ciências Sociais na interdisciplinaridade do planejamento ambiental para o desenvolvimento sustentável. In: CAVALCANTI, C. (org.). Desenvolvimento e natureza: estudos para uma sociedade sustentável. São Paulo: Cortez, 2003.

VALLE, C. E. Qualidade ambiental: ISSO 14000. 4. ed. São Paulo: SENAC, 2002.

Recebido para publicação em 11/08/2014

Revisado em 28/08/2014

Aceito em 15/09/2014 